\title{
Expiration Dates in Automobile Insurance Contracts: The Curious Case of Last Policy Month Claims in Taiwan
}

\author{
Chu-Shiu Li ${ }^{\mathrm{a}, \mathrm{b}}$, Chwen-Chi Liu ${ }^{\mathrm{b}, \mathrm{c}}$ and Sheng-Chang Peng ${ }^{\mathrm{c}}$ \\ ${ }^{a}$ Department of International Business, Asia University, No. 500, Lioufeng Rd., Wufeng, \\ Taichung, 41354, Taiwan. \\ E-mail: chushiu.li@gmail.com \\ ${ }^{\mathrm{b}}$ Risk and Insurance Research Center, National Cheng-Chi University, No. 64, Sec.2, Chinan Rd., \\ Taipei, 11605, Taiwan. \\ E-mail: liuc@fcu.edu.tw \\ ${ }^{c}$ Department of Risk Management and Insurance, Feng Chia University, No. 100, Wenhwa Rd., \\ Seatwen, Taichung, 40724, Taiwan. \\ E-mail: scpeng@fcu.edu.tw
}

This paper investigates a widespread trend in the Taiwanese automobile insurance market in which the loss claims of vehicle damage insurance contracts have a high propensity to occur just before the end of the policy year (as opposed to calendar year). We show that certain uncommon characteristics of claim data are consistently observed in the last policy month. We indirectly show that there is a severe timevarying excess claim problem in this market. The major sources of excess claims can be explained by the bonus-malus system problem and the auto-dealer incentive issue. The Geneva Risk and Insurance Review (2013) 38, 23-47. doi:10.1057/grir.2012.3

Keywords: automobile insurance; excess claim; moral hazard; bonus hunger; bonus-malus system

\section{Introduction}

Insurance contracts are sold every day, and a short-term contract, such as a one-year automobile insurance policy, may become effective any day of the year and expire after 12 months. Traditionally, it is common to use annual data to analyse claim patterns, and insurance claims are supposed to be positively correlated with the length of policy duration in a calendar year. To deal with the unevenness of covered days in a number of different contracts, a weighted procedure based on the effective policy duration in one specific year is needed to take into account the proportional risk exposure period. In their seminal work to test the asymmetric information problem, Chiappori and Salanié ${ }^{1}$ use

\footnotetext{
${ }^{1}$ Chiappori and Salanié (2000).
} 
the number of covered days for each policyholder as a weighted factor to adjust the effective contract period and form a test statistic. Analysing opportunistic fraud in the Canadian automobile insurance with replacement cost endorsement, Dionne and Gagné ${ }^{2}$ utilise the number of months an insurance policy is effective in a target year as the weighted factor for important explanatory variables. These weighting procedures indicate that policy duration is crucial in insurance claim analysis.

In this paper, we examine a unique phenomenon in Taiwan in which a large proportion of claims filed in the last policy month of the automobile insurance contract may not be revealed when the policy duration in the calendar year is used. In other words, what matters is the expiration date based on policy year, not the duration based on calendar year. For example, in the most common comprehensive policy, 32-41 per cent of claims occurred in the last policy month of contracts bought in 2003 and 2004. Given the unpredictable timing of car accidents during the policy period, where policy expiration date and claims are independent, it is unlikely that this pronounced increase in last policy month claims is due to chance.

Of course, there are an uncertain number of legitimate claims occurring randomly every month. However, a policyholder might not report small claims in the early period of a contract to avoid higher future premiums due to several claims. The accumulated small-losses behaviour, or bonus-hunger behaviour, under the bonus-malus system (BMS) seems rational and is well documented in literature. ${ }^{3}$ The market this research explores contains a special BMS in that the first claim in a policy year does not change future premiums. In later sections, we explain the details of BMS and examine its possible role.

In addition, some induced claims may be allowed due to implicit contracts. In our case, the induced claims are defined as unnecessary repairs, such as new paint or replacement of parts, which are common in the Taiwanese automobile insurance market. In particular, this market is characterised by a distinctive marketing system in which automobile insurance and new cars are sold at the same time in the show room. Severe competition among insurers and agents might create a special environment to allow for the existence of the induced claims as part of an implicit contract. In other words, agents (or insurers) implicitly agree that the insured might get something back, for example in terms of unnecessary repairs, at the end of the policy if there are no losses at all during the policy period. We will discuss these possible connections in detail further on.

Lastly, moral hazard and the risk of fraud are always present with insurance contracts. Although broadly recognised, the existence of moral hazard and

\footnotetext{
${ }^{2}$ Dionne and Gagné (2002).

${ }^{3}$ de Pril (1979), Lemaire (1988, 1995) and Walhin and Paris (2000).
} 
insurance fraud is difficult to observe directly. ${ }^{4}$ Similarly, fraudulent claims may not be excluded from our case, but it is impossible to prove them based on the official reported data that we used. Therefore, we do not attempt to identify specific suspicious claims, analysing irregular claim patterns in general instead. ${ }^{5}$

Using a unique data set, we examine several factors associated with claims in the last policy month relative to the first 11 policy months. We propose two major conjectures to clarify the related phenomena, including (i) the BMS problem, and (ii) the auto-dealer incentive issue. The BMS problem is due to the incentive provided by the designation of the BMS in Taiwan, which may come with three extended issues: filing a single claim, accumulating small losses and the motivation to recoup paid premiums. The auto-dealer incentive issue is due to a special automobile insurance sale system, which is often sold with new cars and results in dealer-related agents (DRAs) engaging in "file-and-renew" behaviour. While claims in the last policy month can be attributed to various possible reasons, this phenomenon itself has never been formerly presented by insurers or the government, as all the existing statistical data is displayed based on the calendar year.

Our study contributes to pertinent literature by pointing out the irregular claim behaviours and providing some explanations. We address the question of how the government and insurers react to this irregular claim behaviour, or if they are even aware of it. Previous studies provide plenty of reasons, such as high monitoring costs, revenue maximisation and implicit contractual provisions, as to why insurers do not perform detailed checks on every claim case. Implicit contracts might be a major reason due to the severe competition in the automobile insurance market in terms of high agent commissions and

\footnotetext{
${ }^{4}$ Numerous studies on automobile insurance fraud have been conducted since the 1990s. Derrig et al. (1994) investigate fraud and abuse in Massachusetts' automobile insurance claims; Caron and Dionne (1999) examine similar problems using Canadian data. Cummins and Tennyson (1996) find that attitudes towards fraud significantly affect automobile liability claims. Other papers, such as those by Weisberg and Derrig (1998), Tennyson and Salsas-Forn (2002), Artis et al. (2002) and Caudill et al. (2005) develop techniques to identify or classify fraudulent claims.

${ }^{5}$ If there is a plausible link between claim-related regulations or social environmental factors and claims or claim payments, we may suppose that opportunistic fraud or moral hazard is involved. For example, Abrahamse and Carroll (1998) and Carroll and Abrahamse (2001) analyse soft-injury claim patterns across states that use different types of insurance systems to estimate excess claims in the U.S., finding that approximately 42 per cent of reported soft-injury claims in the dollar-threshold and tort states are for non-existent or pre-existing injuries. Dionne and Gagné (2002) examine a phenomenon in Canada where the probability that a car is stolen significantly increases near the end of a contract that endorses replacement costs, signalling possible opportunistic fraud.
} 
DRA marketing power. Promising some specific car maintenance in advance is definitely good for promoting the sale of certain insurance contracts, although it brings up an ethics issue. However, in order to improve stringent regulations, such as pricing formulas, loading restrictions, etc., imposed on the automobile insurance market by the government, a long-term plan for deregulation was adopted in 2002. By April 2009, premium setting in Taiwan had been fully deregulated. Since then, commissions for agents have dropped by more than 40 per cent. The impact of deregulation on claim behaviour is not covered in this study and may deserve future analysis.

This paper is organised as follows. The next section provides a detailed description of Taiwan's automobile insurance market. The subsequent section presents the empirical data and initial findings. The section after that describes the empirical models and estimation results. The penultimate section discusses the policy implications, and the paper concludes in the final section.

\section{Taiwan's automobile insurance market}

The automobile insurance market in Taiwan is different in many ways from its counterparts in Western countries. It has free entry, although it is highly regulated. Standard pricing formulas, including base premiums, are set by an insurance authority. All insurers share the same information about the claim coefficients of the insured. There is no competition in nominal premiums. Instead, insurers compete in terms of services or returning a commission to the customer. Various kinds of agents and providers play major roles in this market. $^{6}$

Vehicle damage coverage premiums for all policy options are calculated using the official formula to multiply basic premiums with manufactured and insured coefficients, where the manufactured coefficient is closely related to the vehicle age and type and is provided by the insurance authority. The insured coefficient consists of gender-age and claim coefficients, where the former represents immutable characteristics (gender and age) and the latter reflects driving record. For a given age, men have a higher gender-age coefficient than women, ranging from 9 per cent for older men to 19 per cent for younger men. The claim coefficient is obtained by the conversion of cumulative claim points, which are calculated as the sum of no-claim points and claim points for the past three years. The benchmark claim coefficient is zero, and a policyholder who does not file a claim in a given year earns a 0.2 -unit decrease in the claim coefficient, corresponding to a 20 per cent discount in his or her basic premium. Thus, the claim coefficient for a benchmark policyholder who does

\footnotetext{
${ }^{6}$ Bourgeon et al. (2008).
} 
Table 1 Three types of coverage for property damage to vehicles

\begin{tabular}{lcccc}
\hline Insured perils & $\begin{array}{c}\text { Comprehensive } \\
\text { Form } A\end{array}$ & \multicolumn{2}{c}{ Comprehensive Form B } & Form C \\
\cline { 3 - 4 } & & Deductible & No deductible & \\
\hline Rollover & $\mathrm{X}$ & $\mathrm{X}$ & $\mathrm{X}$ & \\
Lightening & $\mathrm{X}$ & $\mathrm{X}$ & $\mathrm{X}$ & \\
Fire (Explosion) & $\mathrm{X}$ & $\mathrm{X}$ & $\mathrm{X}$ & \\
Flying objects & $\mathrm{X}$ & $\mathrm{X}$ & $\mathrm{X}$ & \\
Moving collision & $\mathrm{X}$ & $\mathrm{X}$ & $\mathrm{X}$ & $\mathrm{X}$ \\
Other collision & $\mathrm{X}$ & $\mathrm{X}$ & $\mathrm{X}$ & \\
Vandalism & $\mathrm{X}$ & & & \\
Unknown perils & $\mathrm{X}$ & & & \\
Deductible (NT\$1,000) & $3 / 5 / 7$ & $3 / 5 / 7$ & 0 & 0 \\
Basic premium (NT\$) & 47,096 & 23,119 & 25,433 & 11,918 \\
\hline
\end{tabular}

Source: The Non-Life Insurance Association, Taiwan.

not file a claim becomes -0.2 after one year and -0.6 after three years. A single claim in a given year does not change the claim coefficient, but each subsequent claim adds 0.2 to the claim coefficient. A claim point counts against the policyholder even when the policyholder is not the driver at the time of an accident.

There are three major types of coverage for vehicle damage insurance (Table 1). The comprehensive Form A policy, sold with compulsory deductibles, covers all perils. The comprehensive Form B policy, sold with deductibles or with a zero deductible, covers the same risks as the Form A policy, but excludes vandalism and unknown perils. The moving collision, or Form $\mathrm{C}$ policy, is sold with no deductibles and covers only two-car collisions.

A special automobile insurance distribution channel is used in Taiwan. In contrast to most Western countries where car dealers rarely sell car insurance, providing insurance is an integral part of the car marketing and sales system in Taiwan. Taiwan's car dealers are directly involved with DRAs and may even have their own insurance agents who sell automobile insurance in the showrooms. Consequently, a salesperson often plays dual roles, representing both the dealer and the DRA. A consumer usually buys a new car and insurance at the same time and place. As a result, a DRA enjoys a privileged position to sell insurance. Some insurers rely heavily on DRAs as a major source of business; therefore, when a DRA operates independently, selling several contracts from different insurers, insurers are forced to compete in terms of DRA commissions. Although there are no official figures concerning revenue from various marketing channels, DRAs might account for a high proportion of total automobile insurance premiums sold by some insurers, especially those for new cars. 


\section{Data, preliminary analysis and conjectures}

Data

The data used in this study is unique. We obtained the entire data set of private automobile vehicle damage insurance contracts in Taiwan for the calendar years from 2003 to 2005. In this heavily regulated industry, insurers are required to report the sale of all individual policies to the Taiwan Insurance Institute, a semi-official organisation responsible for collecting insurance statistics and financial data for insurers. The data set includes complete car insurance information from insurers, including characteristics of policyholders, vehicles, claim drivers and contract details. Unfortunately, there is no information available about distribution channels. Therefore, we are not able to directly examine trends in policies secured through direct writers, independent agents or DRAs.

Taiwan's automobile insurance policies are usually valid for one year. As a new policy can become effective any day of the year, we reorganise claim data, originally reported by calendar year, by policy year. This reorganisation is necessary to investigate possible policy period effects in the data.

\section{Preliminary analysis}

Figure 1a illustrates the calendar time distribution of claim frequency - the ratio of claims each month to total policies in that calendar year-for three types of automobile insurance contracts in Taiwan from 2003 to 2004. There is little variation in the share of claims across months for Forms A and B. Claim frequencies for these two policies appear to be slightly higher in December (Forms A, 8 per cent; Form B, 7 per cent) and January (Form A, 8 per cent), as compared to other months ( 4 per cent $\sim 6$ per cent), perhaps due to seasonal conditions. Form $\mathrm{C}$, which covers collision only, reveals a relatively lower ratio of claim frequency (around 1 per cent) for all months.

In contrast, Figure $1 \mathrm{~b}$ presents the period time distribution of claim frequency - the ratio of claims each month to total policies in that policy year-for the three types of contracts in the same years. Claim shares are noticeably different when viewed on the policy time scale instead of on the calendar time scale. ${ }^{7}$ In the 2003 policy year, Forms A and B exhibit high peaks in the last policy month, reaching 7.0 per cent and 7.9 per cent, respectively (vs. 1.5 per cent $\sim 2.5$ per cent for Form $\mathrm{A}$ and 1.2 per cent $\sim 2.3$ per cent for Form $\mathrm{B}$ in the first 11 months). Form $\mathrm{C}$ displays a much lower claim tendency

\footnotetext{
${ }^{7}$ Here, we describe one-year policies sold between 1 January 2003 and 31 December 2004. These correspond to policies expiring between 1 January 2004 and 31 December 2005.
} 
a

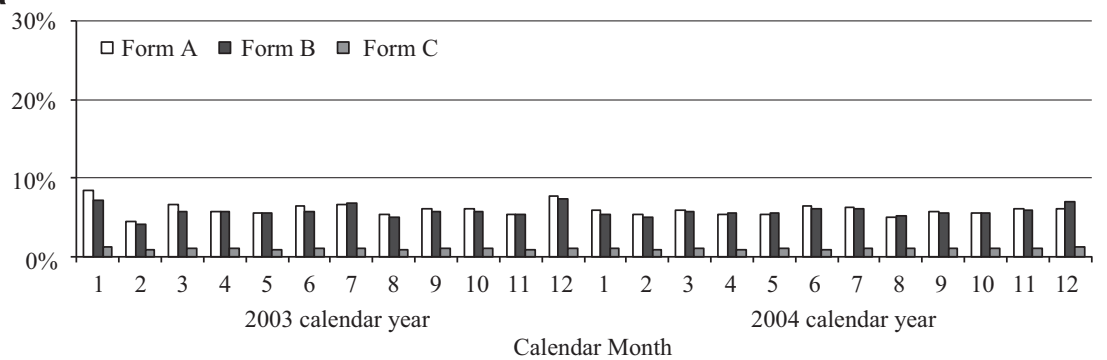

b

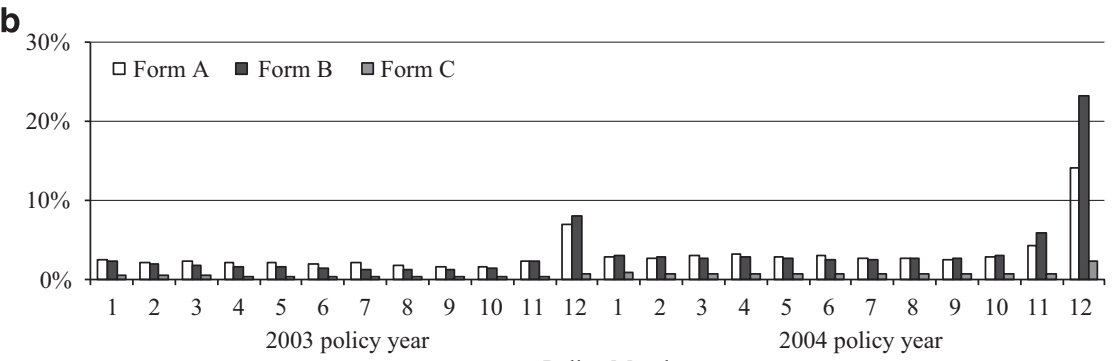

Policy Month

C

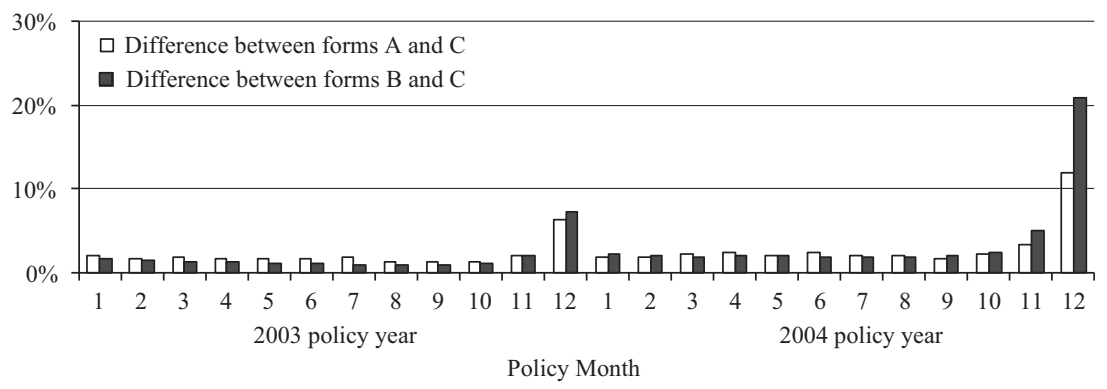

Figure 1. Monthly shares of total claims for Forms A, B and C in policy years 2003 and 2004 : (a) by calendar month; (b) by policy month; (c) the differences in monthly shares of total claims between policy forms A and B vs. C.

Note: Monthly shares of total claims are defined as the ratio of claims each month to the total number of policies in that year.

( 0.2 per cent $\sim 0.6$ per cent) in all policy months. Similar phenomena are even more evident in the 2004 policy year. For Form A and Form B, claim frequencies are 14.1 per cent and 23.2 per cent, respectively, in the last policy month, compared with 2.4 per cent $\sim 5.7$ per cent in other months. 
As different policy forms provide different coverage, we expect that the explanation for the high peak in claims during the last month of the policy year is different for each form. If these claims result from small losses accumulated over the policy year, we would expect fewer Form C claims, as collisions involve two drivers. This phenomenon is apparent in Figure 1c, which shows the differences in monthly shares of total claims between policy forms A and B vs. C. The claim shares are indeed much higher for Forms A and B than they are for Form C. This positive difference is consistent for all policy months and reaches its highest level in the last month of the policy year.

Comprehensive Form B policies, the most common policy type, have the highest frequency of claims. This policy is very popular as the premium for comprehensive Form B is approximately half of that of Form A, and also because Form $\mathrm{C}$ provides less coverage, as shown in Table 1. The period time distributions of claim shares in Figure $1 \mathrm{~b}$ are consistent with these expectations.

On the basis of Figure 1, we may predict that the highest average claim payment (in terms of total policies sold) is in the last policy month. Figure 2a shows the expected tendency. Interestingly, while claim shares spike in the last month of each policy year, we find that claim severity (average payments per claimed policy) is lowest in this month, as illustrated in Figure 2b. For
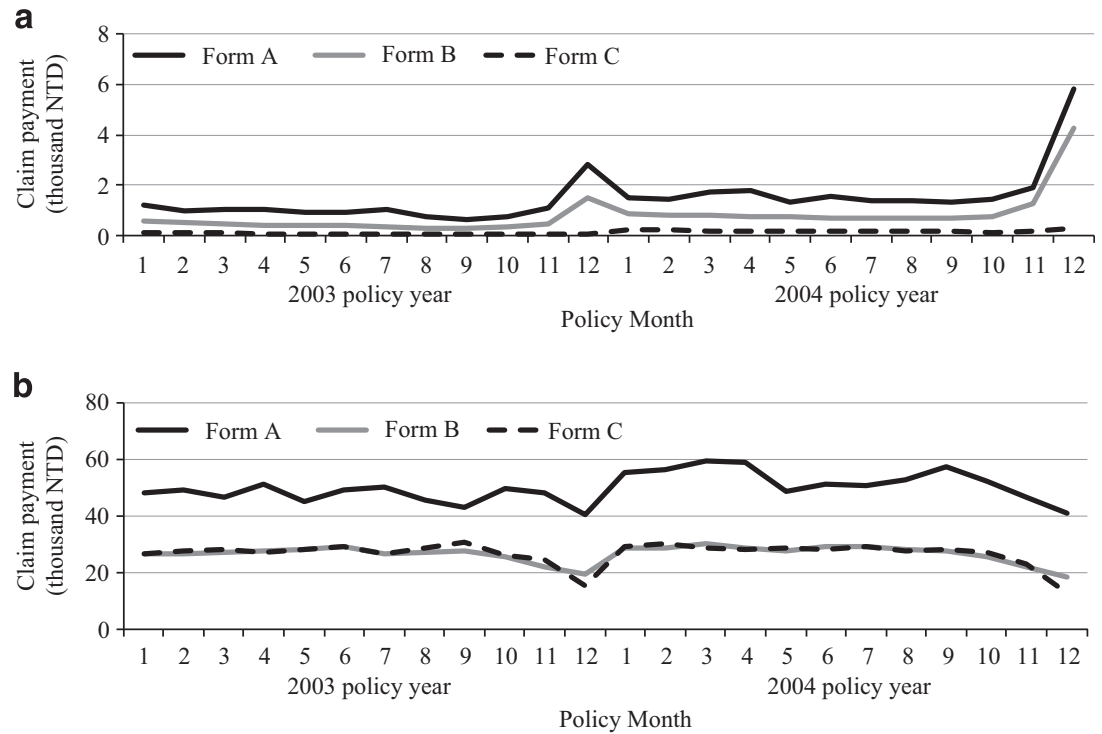

Figure 2. Average claim payments in policy years 2003 and 2004: (a) average claim payments per policy sold; (b) average claim payments per claimed policy. 
example, the average claim payment per claimed policy for Form B is NT\$26,760 for the first 11 policy months in policy year 2003, but only NT NT $\$ 19,300$ in the last policy month - a 28 per cent reduction. ${ }^{8}$ Similar patterns appear in Forms A and C, as well as in the policy year 2004.

\section{Conjectures}

Two major conjectures can be made based on the environment of this regulated automobile insurance market to explain some of the irregular claim patterns. First, the designation of BMS in Taiwan might provide incentive for the insured to file a claim before the end of the policy period. There are three related issues contained in the BMS: filing one claim, accumulating small losses and recouping the paid premium. Since a single claim in a given year does not change the claim coefficient, this creates an illusion that there is no cost involved in filing just one claim (we discuss the real cost of filing one claim in a latter section). In addition, since the claim coefficient depends on the number of claims and not on the claim amount, there is a structural temptation to file a single claim for reimbursement of several small losses. Under the BMS, a policyholder might not report small claims because he or she does not feel that the claim payment sufficiently offsets higher future premiums. ${ }^{3}$ In particular, Lemaire ${ }^{9}$ calculates the average optimal retention and compares the efficiency of BMS in various countries. Although accumulation and retention are similar but not exactly the same, the existence of both situations is possible. As the retention of policyholders is not observable, we focus on the accumulation of small losses.

Another possible reason for excessive claims in the final policy month is the designation by BMS for the recouping of paid premiums; in other words, filing a claim to effectively be reimbursed for the premium already paid. It is common for some insureds to question whether the protection provided by insurance is worthwhile. It is difficult to distinguish between an excessive claim filed as reimbursement for accumulating small losses, and that filed for the recouping of paid premiums. For policyholders who file more than one claim in a policy year, accumulated small losses is a less likely explanation. For these cases, recouping of paid premiums is a more likely explanation, especially when the realised total claim payment is smaller than the premium paid.

The second conjecture is the auto-dealer incentive issue. The DRA, as described in the section "Taiwan's automobile insurance market", might play

\footnotetext{
${ }^{8}$ New Taiwan Dollars (NT\$). On 31 December 2003, the exchange rate was US\$ $1=$ NT\$ 33.98.

${ }^{9}$ Lemaire (1988).
} 
an important role in claim patterns. Since providing insurance is an integral part of the car marketing and sales system in Taiwan, car dealers are directly involved with DRAs who sell automobile insurance in show rooms. The car salesperson, acting as the DRA, occupies a key position in the insurance system. After buying a car and an insurance policy together, a policyholder contacts the salesperson when an accident occurs or a repair is needed. We expect that new cars are closely connected with excessive claims in the last policy month. In practice, purchasing insurance from a DRA together with a new car may form the basis of a short-term relationship that is mutually beneficial, as it provides repeat business for the DRA and is convenient for the policyholder in terms of claim services. The problem is that the salesperson might suggest or even encourage unnecessary repairs, which may or may not be a part of an implicit contract, as an incentive to buy a policy from the DRA. The situation here is similar to that in recent studies focusing on collusion between policyholders and providers. ${ }^{10}$

However, as policyholders rarely renew a policy with DRAs after the first two years, one might hypothesise that the role of DRAs in excess claims decreases with car age and reaches the highest tendency within the first year after a new car is purchased.

In an extension of the role of the DRA, as discussed above, the salesperson contacts the policyholder when the insurance policy approaches expiration, in addition to brokering regular insurance services. Renewing a policy secures additional commissions for the salesperson. Filing a claim in the last policy month and then renewing the policy might signal excess claims induced by DRAs.

In sum, the potential factors related to irregular claims filed in the last policy month are twofold: (1) the designation of BMS without explicitly penalising the claim coefficient for the first claim, which might lead to the accumulation of small losses and the recouping of paid premiums; and (2) the auto-dealer incentives, which are related to an implicit contract with DRAs and a new car. We establish econometric models to examine the impact of these factors on excess claims in the next section.

${ }^{10}$ Ma and McGuire (1997) construct an optimal insurance contract and payment system by taking into account false reporting from doctors and patients. Picard (2000) provides a model in which agents, in charge of marketing channels and not monitored by insurers, might collude with policyholders by offering advantageous contracts to compensate for low promotional efforts. Alger and Ma (2003) show that deterrence of consumer-provider collusion is not optimal unless the probability of collusion is large. Bourgeon et al. (2008) examine a theoretical framework to introduce models in which an insurer develops his or her own network of providers to reduce the cost from collusion between policyholders and providers. 


\section{Empirical analysis}

\section{Variables and descriptive statistics}

Our objective in this section is to more closely examine characteristics of policies with claims filed in the last policy month. As comprehensive Form B policies represent the most widespread claims, we focus on this type of policy, which includes samples with and without increasing per-claim deductibles. A claim exists only if the loss exceeds the deductible, and different deductibles create diverse meanings and frequency of claims. To correct for the problem of consistency with coverage and claims, we subtract the increasing per-claim deductibles from those claims without deductibles. ${ }^{11}$ The variables used in this paper are as follows.

Claim in last policy month: a dummy variable that equals 1 if the claim is filed in the last policy month, and 0 if the claim is filed in months $1-11$.

Claim payment: the dollar amount of the claims paid in the policy period.

New car: a dummy variable that equals 1 if the car age is less than one year, and 0 otherwise.

Renew: a dummy variable that equals 1 if the policy is renewed through the same insurer in the next year, and 0 otherwise.

Any previous claim: a dummy variable that equals 1 if there is at least one claim filed before the last policy month, and 0 otherwise.

Previous claim less than premium: a dummy variable that equals 1 if the total claimed payment received before the last policy month is less than the premiums paid, and 0 otherwise.

Exhaust: the cubic capacity of the automobile.

Claim coefficient: the claim coefficient of policyholder, an indicator of past driving record.

Deductible: a dummy variable that equals 1 if the insurance policy has a deductible, and 0 otherwise.

New policy: a dummy variable that equals 1 if the policy is newly issued (as opposed to renewed), and 0 otherwise.

Imported car: a dummy variable that equals 1 if the car is imported, and 0 otherwise.

Car brand $i$ : a dummy variable that equals 1 if the insured automobile is brand $i, i=1,2, \ldots, 7$, and 0 otherwise.

Region $i$ : a dummy variable that equals 1 if the automobile is registered in region $i, i=1,2,3,4$, and 0 otherwise.

\footnotetext{
${ }^{11}$ For simplicity, a small portion (less than 1 per cent) of policies with straight deductible is excluded.
} 
The Geneva Risk and Insurance Review

34

Table 2 Descriptive statistics of the key variables $(N=489,975$ policies $)$

\begin{tabular}{lrr}
\hline Variable & Mean & Std. dev. \\
\hline Policy with claim(s) & 0.327 & 0.469 \\
Claim in last policy month & 0.159 & 0.366 \\
New Car & 0.524 & 0.499 \\
Renew & 0.208 & 0.406 \\
Any previous claim & 0.207 & 0.405 \\
Previous claim less than premium & 0.123 & 0.329 \\
New policy & 0.717 & 0.451 \\
Deductible & 0.185 & 0.389 \\
Imported car & 0.194 & 0.395 \\
Exhaust $(1000$ c.c.) & 1.893 & 0.473 \\
Claim coefficient & -0.098 & 0.188 \\
Claim count (total policies) & 0.502 & 0.919 \\
Claim count (policy with claims, $N=160,172)$ & 1.534 & 0.998 \\
Claim payment ${ }^{a}$ (total policies) & 9.721 & 28.649 \\
Claim payment ${ }^{a}$ (policy with claims, $\left.N=160,172\right)$ & 29.735 & 43.768 \\
Claim payment in the last policy mont $^{a}(N=77,954)$ & 18.186 & 15.160 \\
2003 policy year & 0.465 & 0.499 \\
\hline
\end{tabular}

${ }^{\mathrm{a}}$ Denotes payment in thousand NT\$.

Insurer $i$ : a dummy variable that equals 1 if the policy belongs to company $i$, $i=1,2, \ldots, 16$, and 0 otherwise.

Table 2 shows that 32.7 per cent of total policies incurred claims in policy years 2003 and 2004. Of these, around half (15.9 per cent) of the policies have claims filed in the last policy month. 52.4 per cent of the insured cars are new, the car's age being less than one year. In addition, only 20.8 per cent of the policies were renewed, 71.7 per cent were new policies and 18.5 per cent had a deductible. Regarding last month claims, 20.7 per cent of the total policies have previous claims in the first 11 policy months, and 12.3 per cent have claim payments that are less than the premium paid.

An average car has a 1,893c.c. engine capacity, which is not unusual in Taiwan (the most popular cars have a capacity of 1,600-2,000c.c.). The average claim coefficient is -0.098 (ranging from -0.6 to 2.8 ), indicating that most policyholders have relatively low claim coefficients. For claimed policies, the average claim payment is NT\$29,735 (ranging from 600 to 4,300,000).

A policyholder's claim coefficient reflects his or her claim history over the past three years. Figure 3 suggests that claim shares in the last policy month peak for policyholders with zero claim coefficients. While this peak is not particularly pronounced, it might reflect the common misperception among policyholders that a claim in one policy year will not affect his or her 


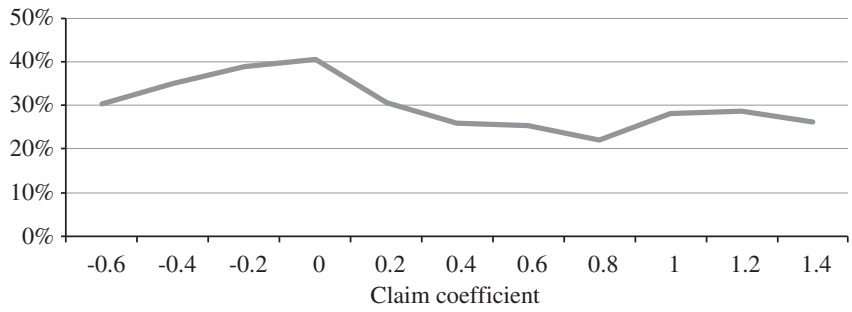

Figure 3. Shares of claims in the last policy month by claim coefficient.

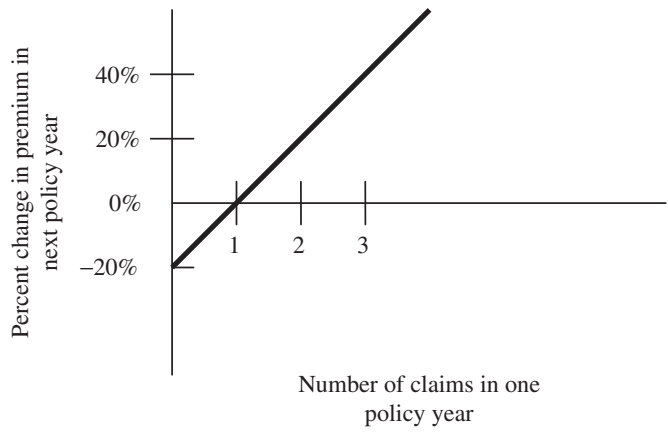

Figure 4. The relationship between number of claims in one policy year and percent change in premium in the next policy year.

future policy terms. Although the claim coefficient for a policyholder who files a single claim in a given year remains unchanged, he or she forgoes the 20 per cent discount in the next year's premium. In fact, the percentage change in future premiums grows linearly with claims in a given policy year (Figure 4).

To obtain a general understanding of claim distribution before formal testing, we examine the claim frequency pattern between new and old cars, and between single claims and more than one claim. Figure 5a shows that both new and old cars have a much a higher ratio of claims that occur in the last policy month during the periods this research examines. In particular, the last month claim ratio for new cars is larger than that for old cars. In 2004, there are twice as many claims on new cars than there are on old cars. A similar situation exists for cases involving one claim vs. cases with more than one claim. For example, in Figure 5b there is high spike in claims filed in the last month both for cases of one claim and for cases of more than one claim. However, the claim ratio for one-claim cases is more than double of that of cases with more than one claim. 
a

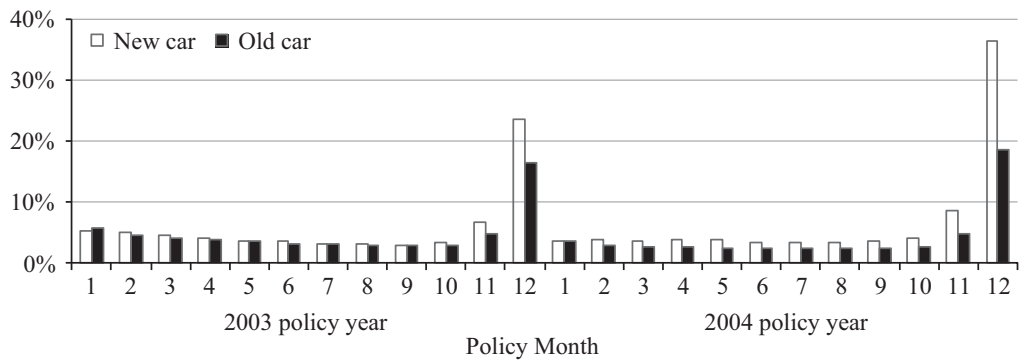

b

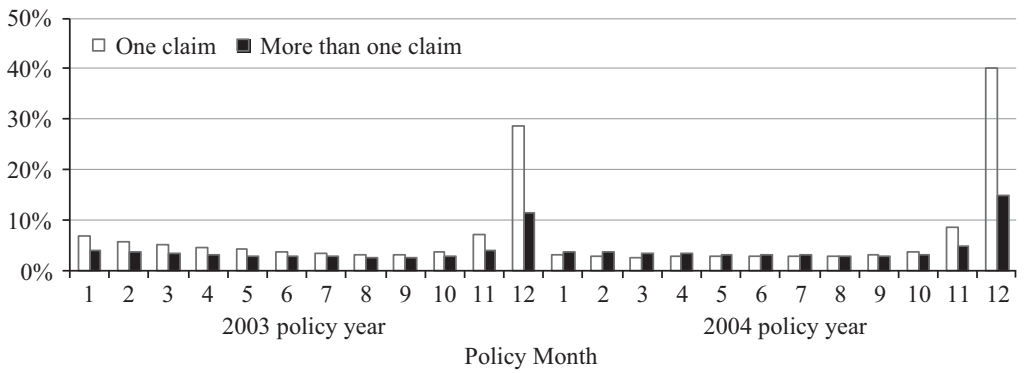

C

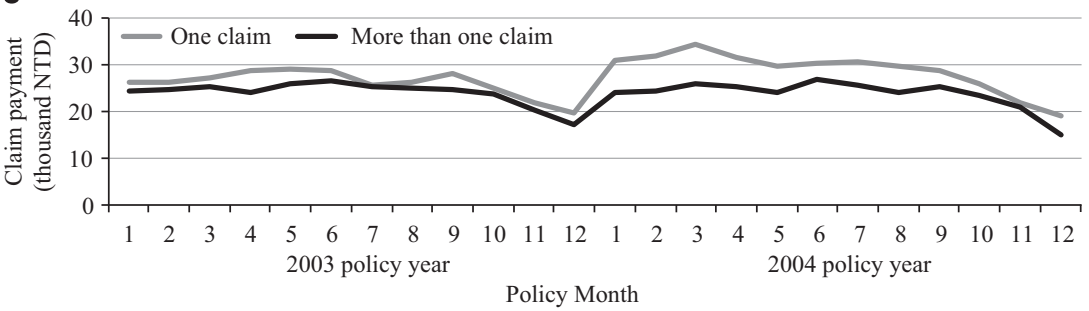

Figure 5. Monthly shares of total claims for policies with new and old cars and for one claim and more than one claim in policy years 2003 and 2004: (a) new car vs. old car; (b) one claim vs. more than one claim; (c) average claim amount: one claim vs. more than one claim.

Figure $5 \mathrm{c}$ provides a further observation on the average claim payments for cases of one claim and more than one claim. The average claim amount is consistently higher for one claim than for more than one claim in each month and reaches the lowest amount in the last policy month of 2003 and 2004. This fact might partly fit with the conjectures mentioned above. For example, a higher amount of one claim might have a connection with the designation of BMS. The lower severity of cases with more than one claim might be partly due to the intended reclaiming of the premium paid. 


\title{
Methodology
}

To verify the conjectures regarding the factors affecting last policy month claims, we use two different regression models. In the first model, we define a binary response variable, Claim in last policy month, as the indicator of whether a claim is filed in the last policy month, and then consider the probit model:

\author{
$\operatorname{Pr}($ Claim in last policy month $)$ \\ $=\Phi($ New car, Renew, New car $*$ Renew, Any previous claim, \\ Previous claim less than premium,
}

Any previous claim * Previous claim less than premium, $\mathbf{X})$,

where $\Phi$ represents the standard normal cumulative distribution function. We include six major variables to test the conjectures discussed in the section "Data, preliminary analysis and conjectures". All other available policy details are included in the predictor matrix $\mathbf{X}$ : car size, policy type and deductible choice. To control for possible effects of insurers, regions, car brands and time, we include dummy variables to reflect 16 insurers, 4 regions, 7 car brands and the policy year 2003 .

In the second model, we use the same explanatory variables to examine factors associated with payments of claimed policy in the last policy month. We take the log of claim payments (in NT\$) as the response variable and consider the variables directly related with claims together with Claim in last policy month. The model is:

$$
\begin{aligned}
& \log (\text { payment for the last month claim }) \\
& =\mathbf{X} \boldsymbol{\beta}+\beta_{1} \text { New car }+\beta_{2} \text { Renew }+\beta_{3}(\text { New car }) *(\text { Renew }) \\
& \quad+\beta_{4} \text { Any previous claim }+\beta_{5} \text { Previous claim less than premium } \\
& \quad+\beta_{6}(\text { Any previous claim }) *(\text { Previous claim less than premium })+\varepsilon
\end{aligned}
$$

where $\beta_{i}$ is the parameter of primary interest, and $\varepsilon$ is an independent and normally distributed error term. We run the log-linear model using claimed data.

\section{Estimation results}

Claim filed in the last policy month

In Table 3, the results of fitting the probit model (Eq. (1)) are presented by Models P1 and P2. The auto-dealer incentive problem is captured by the first three variables: New car, Renew and the interaction term of these two. The estimated results of Models P1 and P2 show that New car is significantly positive at the 1 per cent level, supporting the conjecture described before. However, the coefficient of Renew is insignificant. In other words, policyholders 
The Geneva Risk and Insurance Review

38

Table 3 Probit regression of the policy with a claim filed in the last policy month

\begin{tabular}{|c|c|c|}
\hline Variable & Model P1 & Model P2 \\
\hline New car & $\begin{array}{l}0.2088 * * * \\
(0.0067)\end{array}$ & $\begin{array}{l}0.2066^{* * * *} \\
(0.0071)\end{array}$ \\
\hline Renew & $\begin{array}{r}-0.0095 \\
(0.0059)\end{array}$ & $\begin{array}{r}-0.0075 \\
(0.0081)\end{array}$ \\
\hline New car $\times$ Renew & & $\begin{array}{r}-0.0037 \\
(0.0111)\end{array}$ \\
\hline Any previous claim & $\begin{array}{l}-0.1431 * * * \\
(0.0056)\end{array}$ & $\begin{array}{l}-0.2160 * * * \\
(0.0083)\end{array}$ \\
\hline $\begin{array}{l}\text { Any previous claim } \times \text { Previous claim } \\
\text { less than premium }\end{array}$ & & $\begin{array}{l}0.1170 * * * \\
(0.0099)\end{array}$ \\
\hline Exhaust & $\begin{array}{l}-0.0810^{* * *} \\
(0.0059)\end{array}$ & $\begin{array}{l}-0.0838 * * * \\
(0.0059)\end{array}$ \\
\hline Imported car & $\begin{array}{l}-0.1205^{* * *} \\
(0.0093)\end{array}$ & $\begin{array}{l}-0.1180 * * * \\
(0.0093)\end{array}$ \\
\hline Claim coefficient & $\begin{array}{l}0.6000 * * * \\
(0.0160)\end{array}$ & $\begin{array}{l}0.5878 * * * \\
(0.0160)\end{array}$ \\
\hline Deductible & $\begin{array}{l}-0.0383 * * * \\
(0.0069)\end{array}$ & $\begin{array}{l}-0.0386^{* * * *} \\
(0.0069)\end{array}$ \\
\hline New policy & $\begin{array}{l}0.0475 * * * \\
(0.0072)\end{array}$ & $\begin{array}{l}0.0477 * * * \\
(0.0072)\end{array}$ \\
\hline Intercept & $\begin{array}{c}-0.7935 * * * \\
(0.0272)\end{array}$ & $\begin{array}{l}-0.7909 * * * \\
(0.0273)\end{array}$ \\
\hline Other controls & \multicolumn{2}{|c|}{$\begin{array}{l}\text { Age, Gender and Marital status of policyholder, Insurer, Region, } \\
\text { Car Brand and } 2003 \text { policy year }\end{array}$} \\
\hline Observations used & 489,975 & 489,975 \\
\hline Log Likelihood & $-181,578.4088$ & $-181,507.5374$ \\
\hline
\end{tabular}

Note: Standard errors in parenthesis.

*** Statistical significance at the 1 per cent level.

with a new car are more likely to file claims in the last policy month, while policyholders who are renewing a policy in the next year do not have a strong tendency to do so. The automobile physical damage insurance market in Taiwan mostly relies on new car business (52.4 per cent, Table 2), which is dominated by DRAs. Renewed policies account for 20.8 per cent only. ${ }^{12}$ It is critical for DRAs to seize the opportunity for selling insurance policies that comes from new cars by offering last month claim incentives. In Model P2, the interaction term between New car and Renew is added. The coefficient is

\footnotetext{
12 This ratio is obtained from the policies renewed by the same insurer. We are not able to identify the policies switched to or from different insurers.
} 
insignificant, confirming that new car policyholders who renew the policy in the next year are not related to filing a claim at the end of the policy year. Since the percentage of renewed policies (with the same insurer) of a new car is very low, it implies that an expiration date effect is strong for new car policies and has nothing to do with renewal.

To investigate the BMS issue, the motivation of the insured to file a last policy month claim is examined by the related variables of previous claims: Any previous claim, Previous claim less than premium and the interaction term. In Table 3, the coefficients of Any previous claim in both Models P1 and P2 are significantly negative. This reveals that those insured tend not to file last month claims if they have previous claim experience. This finding is consistent with our expected results, that a policyholder who files one claim only (in which case, Any previous claim is 0) tends to have a last month claim. The design of the BMS, which allows the insured to have one claim in a policy year without increasing the premium in the next year, might encourage policyholders to adopt a "file once in the last policy month" mindset.

To verify the motive of recouping a premium, the interaction term between Any previous claim and Previous claim less than premium is presented in Model $\mathrm{P} 2$, and the coefficient is significantly positive at the 1 per cent level. That is, policyholders may be tempted to file a claim before their policies expire, possibly to ensure that they get back a part or most of the paid premiums. Therefore, Previous claim less than premium can be an indicator that reflects the tendency to file another claim before the policy ends. This result is consistent with our conjecture regarding recouping of premiums.

For other control variables, cubic capacity of the automobile (Exhaust) is also significantly negative and consistent with our observation that smaller cars are more likely to be involved in a last policy month claim. One would expect that large cars are less likely to incur losses in the last policy month for two reasons: a wealth effect and a factory-made effect. The wealth effect refers to policyholders who earn higher incomes, and thus buy larger cars; they may care less about buying insurance without seeing a tangible return. In addition, due to the high quality of factory-made paint, owners of higher valued cars (Imported car) may have less need to have their cars repainted, which is a common cause for claim in the last policy month based on conventional wisdom.

Claim coefficient is positively correlated with the probability of incurring a claim in the last policy month. Policyholders who have been reimbursed in the previous three years (and thus have higher claim coefficients) have more incentive to file a claim again at the end of the policy period, while low-risk policyholders do not. With particular attention to the penalty of a higher claim coefficient, and therefore higher future premiums associated with additional claims, we find that after comparing the basic premium and related figures, the 
average benefit of the 20 per cent premium discount for the first claim is much lower than the average claim amount (not shown). Thus, the BMS is at best a minor deterrent for policyholders to file excess claims since the marginal benefit (indemnity) is much higher than the marginal cost (lost premium discount).

Since more than 80 per cent of policyholders with comprehensive Form B policies prefer not to have a deductible, we examine the effect of the choice for a deductible in the pooled data. The results show that the probability that a claim is filed in the last policy month is significantly lower for policies with a deductible. This finding is consistent with insurance theory, which argues that deductibles might mitigate moral hazard.

Compared with New car, the variable of New policy has a broader range and contains additional policies switched from other insurers. The estimated coefficient of New policy is significantly positive at the 1 per cent level, which is similar to New car, implying that policies newly issued are more likely to have claims in the last policy month.

\section{Claim payments}

Results from fitting the regression model of claim payments in the last policy month are reported in Table 4. We focus on the same key variables related to our hypotheses: New car, Renew, Any previous claim, Previous claim less than premium and interaction terms. Model L1 presents the basic results. The coefficient of New car is significantly negative, reflecting the lower claim amount tendency in the last policy month for a new car. Similar significantly negative effects are also found for Any previous claim. In contrast with the high share of claims at this time, the low claim payment seems to suggest an intentional adjustment of claim amounts in excess claims. We explore this further by including the interaction terms between New car and Renew, and between Any previous claim and Previous claim less than premium in Model L2. Again, the empirical evidence indicates that claims involving previous claims less than premiums paid do have smaller indemnity in the last policy month.

It is worth noting that policies renewed in the following policy year are more likely to have a higher claim amount before the end of policy year in the current year. The role of Renew in the last policy month claim amount is opposite to that of the claim probability.

The effect of whether the policy carries a deductible on claim behaviour is well documented. Among others, Dionne and Gagné ${ }^{13}$ verify the existence of padding claims to offset a higher deductible, especially when the probability of being audited is small. In Table 4, the estimated coefficients of deductible in

\footnotetext{
${ }^{13}$ Dionne and Gagné (2001).
} 
Table 4 Log-linear regression of claim payments in the last policy month

\begin{tabular}{lcc}
\hline Variable & Model L1 & Model L2 \\
\hline New car & $-0.0177^{* * *}$ & $-0.0142^{* * *}$ \\
& $(0.0048)$ & $(0.0051)$ \\
Renew & $0.0517^{* * *}$ & $0.0563^{* * *}$ \\
New car $\times$ Renew & $(0.0039)$ & $(0.0058)$ \\
& & -0.0079 \\
Any previous claim & $-0.3371^{* * *}$ & $(0.0075)$ \\
& $(0.0038)$ & $-0.2889^{* * *}$ \\
Any previous claim $\times$ Previous claim & & $(0.0059)$ \\
less than premium & & $-0.0719^{* * *}$ \\
Exhaust & $0.2453^{* * *}$ & $(0.0068)$ \\
& $(0.0042)$ & $0.2471^{* * *}$ \\
Claim coefficient & $0.1375^{* * *}$ & $(0.0042)$ \\
& $(0.0128)$ & $0.1474^{* * *}$ \\
Deductible & $-0.0900^{* * *}$ & $(0.0129)$ \\
& $(0.0048)$ & $-0.0902^{* * *}$ \\
Imported car & $0.1709^{* * *}$ & $(0.0048)$ \\
& $(0.0067)$ & $0.1696^{* * *}$ \\
New policy & -0.0043 & $(0.0067)$ \\
Intercept & $(0.0051)$ & -0.0040 \\
& $2.3856^{* * *}$ & $(0.0052)$ \\
Other controls & $(0.0190)$ & $2.3831^{* * *}$ \\
Observations used & $(0.0191)$ \\
Log Likelihood & Age, Gender and Marital status of policyholder, Insurer, Region, \\
\hline Cor Brand and 2003 policy year & 77,954 \\
& 77,954 & $-46,599.2972$ \\
\hline
\end{tabular}

Note: Standard errors in parenthesis.

*** Statistical significance at the 1 per cent level.

Models L1 and L2 are negative and significant, which is contrary to the findings of Dionne and Gagné ${ }^{13}$ that a deductible is associated with higher claim payments.

Other control variables have the expected sign, for example, that larger cars (Exhaust), or more expensive cars (Imported car) will incur higher claim amounts. Policyholders with bad driving experiences (Claim coefficient) tend to have higher loss.

\section{Discussion}

On the basis of the empirical evidence obtained in the previous section, we discuss further points associated with last policy month claims. 


\section{The role of the BMS}

As discussed in the section "Data, preliminary analysis and conjectures", the BMS in Taiwan might strongly encourage a policyholder to file only a single claim because this will not change the claim coefficient. Coincidentally, Lemaire argues that a good BMS should "introduce penalties for the first claim as severe as commercially possible, especially in the lower classes ... Never forgive the first claim, whatever the pressure of the marketing department (p. 681)." Lemaire's view does provide an interesting concept for the designation of BMS.

Theoretically, a minimal level of benefit is needed for both parties for the incentives of collusion to be worthwhile. This threshold is likely met in Taiwan when a policyholder can obtain excess claim payments to recoup paid premiums, while a salesperson can receive additional revenue in the form of commissions for renewed contracts as well as directly from car repair garages. ${ }^{14}$ However, this explanation of incentives for policyholders is incomplete since there are both positive and negative effects for policyholders. Some policyholders may feel that the policy is not worth the premium if there is no accident. For these policyholders, filing an excess claim to partially recoup paid premiums may be attractive. Nevertheless, Taiwan's BMS penalises the policyholder for the additional claim by increasing his or her claim coefficient, and thereby increasing future premiums. Therefore, the benefit of the excess claim is diminished so that this penalty serves as a partial deterrence for excess claims. In practice, however, some policyholders might be under the illusion mentioned in previous sections that a single claim will not bear any cost. Some policyholders might not understand this aspect of the BMS, and it is possible that an unscrupulous salesperson exploits this information asymmetry. For these reasons, the deterrent effect of the BMS is weakened. ${ }^{15}$ In sum, it is plausible that at least some policyholders feel there is a net positive incentive to report unnecessary claims.

At first glance, this observation seems consistent with the results of Dionne and Gagne, ${ }^{2}$ namely that the probability that a car is stolen significantly increases with the endorsement of a replacement contract, confirming evidence of opportunistic fraud. However, the nature of the incentive mechanism at play in our study is somewhat different from the one they describe. The case in

\footnotetext{
${ }^{14}$ Mayers and Smith (1981) and Picard (2000) mention that independent agents are more likely to side with consumers when a claim is filed in order to secure a policy renewal from that consumer.

${ }^{15}$ Some policyholders may even believe that agents have their best interest in mind when they propose filing excess claims, possibly as a carry-over of trust earned by the agents in their other roles.
} 
Dionne and Gagné ${ }^{2}$ is one-way fraud, in which the origin of cheating comes from policyholders and has nothing to do with other participants in the market. In contrast, the excess claims in our study come from several different sources: the self-motivated insured and perhaps a kind of soft collusion between agent (including DRAs) and car owner. Nevertheless, it is not easy for the insured to independently file an unsubstantiated claim in the last policy month.

\section{Who is responsible?}

It is debatable whether policyholders or insurance agents are more often responsible for initiating excess claims, whether or not soft fraud or collusion is involved. While the inter-relationships among auto-insurer, insurance agent and policyholder are very similar to those for medical insurer, physician and patient in the situation of "induced demand" in standard medical insurance literature, ${ }^{16}$ an important difference is who is the decision-maker. Patients usually have insufficient knowledge to judge if a specific treatment is needed without the guidance of doctors. Therefore, doctors are responsible for much, if not all, of the induced demand for unnecessary medical care. In contrast, policyholders know if their cars have been in accidents and if consequent repairs are required. Even if insurance agents suggest or encourage policyholders to file excess claims, the final decisions are made by the insured. While there may be a grey area for the utility of an extra medical test, lying about the date of an accident or filing accumulated small losses as a single claim constitutes a breach of good faith inherent in the insurance contract.

\section{How do the insurers react?}

There is a missing part of the story: Why do rational insurers tolerate excess claims, if any? Several explanations are possible: high monitoring costs, revenue maximisation, equilibrium contractual provisions and regulated pricing rule.

First, as Mayers and Smith ${ }^{17}$ stated, "Various ways of verifying the incidence and loss amount are available. Effective competition among insurance firms assures that the monitoring procedures employed will be provided in the least costly form (p. 412)". In this sense, insurers do not audit suspicious cases when costs are high enough, representing costly state verification in the standard theoretical framework. ${ }^{18}$ As we have shown, average claim amounts are

\footnotetext{
${ }^{16}$ See for example Arrow (1963) and Rossiter and Wilensky (1984).

17 Mayers and Smith (1981).

18 Two major theoretical approaches to examine insurance fraud are costly state verification and costly state falsification (see Picard (2000) for a detailed survey).
} 
relatively low in the last policy month and do not attract additional attention from insurers. This situation is consistent with characteristics of the incentivecompatible contract, ${ }^{19}$ in which policyholders intentionally adjust claim amounts to evade verification and auditing. Even if only sometimes successful, this strategy helps to explain how the expiration date effect persists without triggering more investigations from insurers.

Second, premium revenue is one of the key performance indicators of insurers. From the viewpoint of some managers, maximising revenue is perhaps preferred to maximising profit ${ }^{20}$ as the former is a daily pressure while the latter is only reviewed after a specific period, and there is no clear-cut chain of responsibility for suboptimal profits. In addition, although excess claims are generally known to exist, automobile insurance remains a major product line in property insurance.

Third, by relying on agents as one of their largest distribution channels, insurers are more likely to look the other way as long as general loss ratios fall in an acceptable range. Jou and Hebenton ${ }^{21}$ observe the case in Taiwan where the insurers "have no motivation or ready capacity to further investigate the relatively 'small' amount of suspicious claims (p. 124)". In our case, accepting some excess claims from agents forming contractual provisions to maintain business relationships with agents and policyholders seems to create equilibrium in this market.

Fourth, the fact that insurance pricing during the study period has been determined by authorities might also play a role. On the basis of the standard pricing formula, although insurers do not compete over prices, the pricing authorities must set prices that allow insurers to earn a normal rate of return. ${ }^{22}$ In this situation, the official pricing rule must contribute to insurers' willingness to permit the claiming practices.

\section{Conclusion}

This paper analyses insurance claims in Taiwan's automobile insurance market. We find that shares of claims are significantly higher in the last policy month. Motivated by concerns about the special environment of automobile insurance sales, the BMS, and an unethical attitude of the insured towards insurance premiums in Taiwan, we use an extensive data set to investigate the

\footnotetext{
${ }^{19}$ Picard (2000).

${ }^{20}$ Baumol (1967).

21 Jou and Hebenton (2007).

${ }^{22}$ In fact, the return is even higher (see Li et al., 2010).
} 
evidence for several explanations of excess claims near the expiration of insurance policies.

On the basis of the period time distribution of claim payments in the policy year, we provide two major conjectures on the last policy month claims. The empirical results support those conjectures in that policyholders without previous claims in the first 11 months have a higher propensity to file claims before the end of the policy period. And this fact might be connected with the design of the BMS in which "one claim does not increase future premium". In addition, new cars are also more likely to incur claims in the last policy month. Most importantly, a policyholder has more incentive to report one more claim near the expiration date when the realised total claim payment is smaller than the premium paid, supporting the conjecture of recouping of paid premiums.

While always present in insurance contracts, the expiration date has particular importance for short-term policies. What matters is not the magnitude of insurance coverage but the costs and benefits of filing a claim as the expiration date approaches. Our investigation suggests practical steps for mitigating excess claims: (1) implementing a direct repair programme, (2) adopting new auditing procedures that target last policy month claims with the characteristics identified in this paper, such as the "red flags strategy" proposed by Dionne et al., ${ }^{23}$ (3) raising awareness that filing a single claim implies a higher premium in the next year than if no claim is filed.

\section{Acknowledgements}

We are grateful to the editor and two anonymous referees for comments that greatly improved this paper. We also thank Montserrat Guillen and participants at the EGRIE seminar (2008) for helpful comments and the Taiwan Insurance Institute for providing the relevant data. Financial support from the National Science Council, Taiwan, ROC (Grant No. 96-2416-H-035-009-MY2 for Chwen-Chi Liu) is gratefully acknowledged.

\section{References}

Abrahamse A. Carroll S.J. (1998) 'The frequency of excessive claims for automobile personal injuries', in G. Dionne and C. Laberge-Nadeau (eds.) Automobile Insurance: Road Safety, New Drivers, Risks, Insurance Fraud and Regulation. Boston, MA: Kluwer.

Alger I. Ma C.-T. (2003) 'Moral hazard, insurance, and some collusion', Journal of Economic Behavior and Organization 50(2): 225-247.

Arrow K. (1963) 'Uncertainty and the welfare economics of medical care', American Economic Review 53(5): 941-969.

${ }^{23}$ Dionne et al. (2009). 
Artis M. Ayuso M. Guillen M. (2002) 'Detection of insurance fraud with discrete choice models and misclassified claims', Journal of Risk and Insurance 69(3): 325-340.

Baumol W. (1967) Business Behavior, Value and Growth rev. edn., New York: Harcourt, Brace \& World.

Bourgeon J.-M. Picard P. Pouyet J. (2008) 'Providers affiliation, insurance and collusion', Journal of Banking and Finance 32(1): 170-186.

Caron L. Dionne G. (1999) 'Insurance Fraud Estimation: More Evidence from Quebec Automobile Insurance Industry', in G. Dionne and C. Laberge-Nadeau (eds.) Automobile Insurance: Road Safety, New Drivers, Risks, Insurance Fraud and Regulation, Boston, MA: Kluwer.

Carroll S. Abrahamse A. (2001) 'The frequency of excess auto personal injury claims', American Law and Economics Review 3(2): 228-250.

Caudill S. Ayuso M. Guillen M. (2005) 'Fraud detection using a multinomial logit model with missing information', Journal of Risk and Insurance 72(4): 539-550.

Chiappori P. Salanié B. (2000) 'Testing for asymmetric information in insurance markets', Journal of Political Economy 108(1): 56-78.

Cummins J.D. Tennyson S. (1996) 'Moral hazard in insurance claiming: Evidence from automobile insurance', Journal of Risk and Uncertainty 12(1): 29-50.

de Pril N. (1979) 'Optimal claim decisions for a bonus-malus system: A continuous approach', Astin Bulletin 10(2): 215-222.

Derrig R.A. Weisberg H.I. Chen X. (1994) 'Behavioral factors and lotteries under no-fault with a monetary threshold: A study of Massachusetts automobile claims', Journal of Risk and Insurance 61(2): 245-275.

Dionne G. Gagné R. (2001) 'Deductible contracts against fraudulent claims: Evidence from automobile insurance', Review of Economics and Statistics 83(2): 290-301.

Dionne G. Gagné R. (2002) 'Replacement cost endorsement and opportunistic fraud in automobile insurance', Journal of Risk and Uncertainty 24(3): 213-230.

Dionne G. Giuliano F. Picard P. (2009) 'Optimal auditing with scoring: Theory and application to insurance fraud', Management Science 55(1): 58-70.

Jou S. Hebenton B. (2007) 'Insurance fraud in Taiwan: Reflections on regulatory effort and criminological complexity', International Journal of the Sociology of Law 35(3): 127-142.

Lemaire J. (1988) 'A comparative analysis of most European and Japanese bonus-malus systems', Journal of Risk and Insurance 55(4): 660-681.

Lemaire J. (1995) Bonus-Malus Systems in Automobile Insurance, Boston, MA: Kluwer Nijhoff.

Li C. Liu C. Lin C. Venezian E. (2010) 'Pricing effectiveness and regulation: An examination of premium rating in Taiwan automobile insurance', Geneva Papers on Risk and Insurance-Issues and Practice 35(S1): s68-s81.

Ma C.-T. McGuire T. (1997) 'Optimal health insurance and provider payment', American Economic Review 87(4): 685-704.

Mayers D. Smith C.W. (1981) 'Contractual provisions, organizational structure and conflict control in insurance markets', Journal of Business 54(3): 407-434.

Picard P. (2000) 'Economic Analysis of Insurance Fraud', in G. Dionne (ed.) Handbook of Insurance Boston, MA: Kluwer Academic Publishers.

Rossiter L. Wilensky G. (1984) 'Identification of physician-induced demand', Journal of Human Resources 19(2): 231-244.

Tennyson S. Salsas-Forn P. (2002) 'Claims auditing in automobile insurance: Fraud detection and deterrence objectives', Journal of Risk and Insurance 69(3): 289-308.

Walhin J.F. Paris J. (2000) 'The true claim amount and frequency distributions within a bonusmalus system', Astin Bulletin 30(2): 391-403.

Weisberg H.I. Derrig R.A. (1998) 'Quantitative methods for detecting fraudulent automobile bodily injury claims', AIB Filing on Fraudulent Claims Payment, Department of Insurance Docket G93-24, Boston, MA: Automobile Insurers Bureau of Massachusetts. 


\begin{abstract}
About the Authors
Chu-Shiu Li is Professor in the Department of International Business at Asia University, Taichung, Taiwan, and Research Fellow in the Risk and Insurance Research Center, National Cheng-Chi University, Taipei, Taiwan.

Chwen-Chi Liu is Professor in the Department of Risk Management and Insurance at Feng Chia University, Taiwan, and Research Fellow in the Risk and Insurance Research Center, National Cheng-Chi University, Taipei, Taiwan.
\end{abstract}

Sheng-Chang Peng is Post Doctor in the Department of Risk Management and Insurance at Feng Chia University, Taiwan. 